Check for updates

Cite this: RSC Adv., 2019, 9, 14372

\title{
Recovery of extra-heavy oil and minerals from carbonate asphalt rocks by reactive extraction
}

\author{
Xingang Li, ${ }^{\text {abc }}$ Renzhou Bian, ${ }^{\text {ab }}$ Junyan Wang, ${ }^{\text {ab }}$ Xianyi Wang, ${ }^{\text {ab }}$ Jun Ma, ${ }^{\text {ab }}$ \\ Guoqiang Ma, (D) ab Hong Sui ${ }^{\text {abc }}$ and Lin He (ID *ab
}

Quite different from the Canadian oil sands, the Indonesian asphalt rocks proved to be carbonate unconventional oil ores. The strong interactions between asphalt and minerals make water-based extraction work poorly in separating this kind of ore. Herein, a reactive extraction process has been proposed to separate asphalt and mineral solids from the ores through dissolving the mineral solids (i.e., carbonate minerals, metal oxides, etc.) by acids (formic acid). It is evidenced that most of the asphalt could be recovered and collected on the top of the solution by generated $\mathrm{CO}_{2}$. What's more, the unreacted formic acid could be recycled in this process. The dissolved metal ions could be efficiently recovered to obtain different by-products by chemical settling and crystallization. The amount of residual solids settled at the bottom of the reactor is very small. Further tests show that the reaction efficiency is highly dependent on the operational conditions, including temperature, stirring rate, acid dosage, concentration of acid, etc. It is also found that the reaction could allow minerals to be redistributed in different phases. Although some metal elements could be dissolved into solution, elements such as $\mathrm{Fe}, \mathrm{Al}, \mathrm{S}, \mathrm{Si}$, and $\mathrm{Ti}$ are observed to accumulate in asphalt froth. In addition to reacting with minerals, formic acid is also found to reduce asphalt viscosity. This reduction improves the reaction efficiency. Based on primary evaluations, the above findings suggest that the reactive extraction would be a potential process to exploit the Indonesian asphalt rocks (or other similar ores) due to its full recovery to all materials.

Received 16th March 2019 Accepted 25th April 2019

DOI: $10.1039 / c 9 r a 02025 j$

rsc.li/rsc-advances

\section{Introduction}

Carbonate unconventional oil ores are a kind of unconventional oil resource with huge reserves and wide distribution. They have been regarded as an alternative of crude oils. ${ }^{1}$ Indonesian asphalt rock is a carbonate unconventional oil ore with the advantages of high oil content (20-50 wt\% of ores) and huge reserves $\left(\sim 1\right.$ billion barrels in situ). ${ }^{2,3}$ Different technologies have been proposed for asphalt recovery. The hot water-based extraction (HWBE) process has been industrialized in Alberta, Canada, but it has been proved to perform poorly in separating carbonate unconventional oil ores. This is because the interaction between oil and carbonate solid is strong. ${ }^{4-7}$

To unlock this kind of unconventional oil ore, two other different methods have been proposed, including solvent extraction and pyrolysis. ${ }^{8-17}$ Sui et al. investigated the feasibility of solvent extraction in recovering asphalt from Indonesian asphalt rocks. They found that a high oil recovery (up to 98\%)

${ }^{a}$ School of Chemical Engineering and Technology, Tianjin University, Tianjin, 300072, China.E-mail: linhe@tju.edu.cn

${ }^{b}$ National Engineering Research Center of Distillation Technology, Tianjin 300072, China

${ }^{c}$ Collaborative Innovation Center of Chemical Science and Engineering, Tianjin, 300072, China could be achieved with the solvent of toluene or cyclohexane. However, the amount of solvents lost in the residual solids would account for $20 \%$ of the residual solids. Although most of them could be removed and recovered, there were still large amounts of solvent loss. ${ }^{10}$ To improve this situation, great efforts have been made. ${ }^{18-22}$ For example, Sui et al. proposed the application of switchable solvent to recover the asphalt. They obtained a high asphalt recovery of $97 \%$ and the switchable solvent could be recovered easily. ${ }^{18}$ Zhang et al. developed a hybrid process using the amino acid ionic liquid-based deep eutectic solvents for the asphalt rocks separation. The heavy hydrocarbons recovery was up to $93.04 \%$ and the solvent entrainment in the waste solids was highly inhibited. ${ }^{20}$ They obtained excellent results, while these new methods were beyond applications at present due to high cost on both chemicals and operation. Some researchers believed that pyrolysis would be a potential way for the exploitation of the Indonesian asphalt rocks, ${ }^{15,23-25}$ because the asphalt could be directly cracked into light oil fractions or gases without adding external chemicals. However, there are also some challenges during its industrialization, such as high energy consumption, high production of tars together with minerals, large production of gases, especially $\mathrm{CO}_{2}$, etc. ${ }^{13,26}$ 
Due to the limitations of above processes, it is imperative to develop other efficient separation methods for the exploitation of carbonate asphalt rocks. Inspired by the dissolution of carbonate minerals in acids and the main composition of carbonate in carbonate asphalt rocks, a reaction process was proposed to separate asphalt from ores. Even though, there were many works about the utilization of acids to dissolve carbonate ores in the fields of the third oil recovery and hydrometallurgy. ${ }^{27-29}$ Limited work about acid reacting with carbonate to separate asphalt have been reported. Previous work showed that about $45 \%$ calcium carbonate in asbuton rock could be dissolved into the mixture of carbonic acid and $0.5 \mathrm{M} \mathrm{NaCl}$ at 3 bar and $90{ }^{\circ} \mathrm{C}^{27}$ However, the reaction conditions in their works are harsh and the dissolution efficiency is low. Furthermore, little information about the detailed reactions during the extraction was reported, as well as the mechanisms. It is imperative to choose a more advantageous acid solution and reveal the mechanisms of the reactive extraction.

The choice of acid is critical for leaching rocks. There are many previous works on acid leaching carbonate minerals which provide the basis for the acid selection in this article. ${ }^{30-32}$ Inorganic acids including $\mathrm{HCl}$ and $\mathrm{H}_{2} \mathrm{SO}_{4}$ are usually applied in mineral leaching because of its strong acidity. However, concentrated hydrochloric acid has strong volatility and lower solubility, and sulfuric acid is not applied to leach carbonate. Organic acids were always used in acid leaching because of its selectivity and lower corrosivity, especially formic acid and acetic acid. ${ }^{33}$ Gharabaghi et al. used organic acids including formic acid to reduce the content of gangue minerals such as carbonate in phosphate rocks. It is found that formic acid is the optimal acid for this ore which could enrich the content of phosphate rock to $30 \% .{ }^{28}$ Nierode et al. used formic acid and acetic acid to react with limestone, and they found the limiting step of this reaction is mass transport. ${ }^{34}$ Raza et al. explored the dissolution of magnesite by formic acid. The magnesium carbonate would be dissolved in formic acid. They obtained a high recovery of magnesite at $84.9 \% .^{35}$ Other primary tests have also been conducted to understand the dissolving capacity of acids in dissolving the calcium carbonate. ${ }^{34,36}$ However, little research focuses on acid reacting with carbonate asphalt rocks to recover extra-heavy oil. Therefore, formic acid was chosen in this work to react with asphalt rock because of its organic properties which would help to reduce asphalt viscosity comparing to inorganic acid as well as its stronger acidity among organic acid. Besides, the by-products of calcium formate were more valuable than other simple acids.

\section{Concept of reactive extraction process}

Different from the traditional exploitation of unconventional oil ores, an attempt comes to us if we can recover both oil and minerals during the separation of asphalt rocks from the atom economy point of view, each element should be used or converted into products during the chemical processes. Keep this idea in mind and carefully analyze the chemical composition of the asphalt rocks, we find the possibility of the 'full recovery' process to the asphalt rocks by reactive extraction. As shown in Fig. 1, a schematic of reactive extraction to recover all of materials from the asphalt rocks has been proposed. In briefly, the carbonate asphalt rocks are mixed with acid in the reactor where minerals react with acid. The generated $\mathrm{CO}_{2}$ from the reaction would help to float the asphalt. The floated asphalt froth was collected and further diluted with solvents for separation of entrained solids and water. These separated solids will be transferred for further reaction with acid. The unreacted solid from the primary reaction and the secondary reaction are collected and easily cleaned for specific applications. The dissolved minerals in the solution could be recovered by chemical precipitation, crystallization. The $\mathrm{CO}_{2}$ could also be collected and recovered for potential applications.

The reactive extraction is hoped to relieve tailing treatment issue by recovering both asphalt and metal minerals. Due to low content of gravels, the amount of solvents used in the subsequent asphalt froth cleaning process will be reduced sharply. This novel reactive extraction possesses the advantages of not only recovering asphalt and metal elements, but also reducing tailing accumulation. To develop this concept into a no waste and full resource recovery process, we had an attempt to verify the feasibility of reactive extraction process for Indonesian asphalt rocks by bench scale laboratory tests in this study.

Accordingly, in this work, the reactive extraction process will be implemented to separate and recover asphalt from the Indonesian asphalt rocks using formic acid. ${ }^{37}$ The recovery of

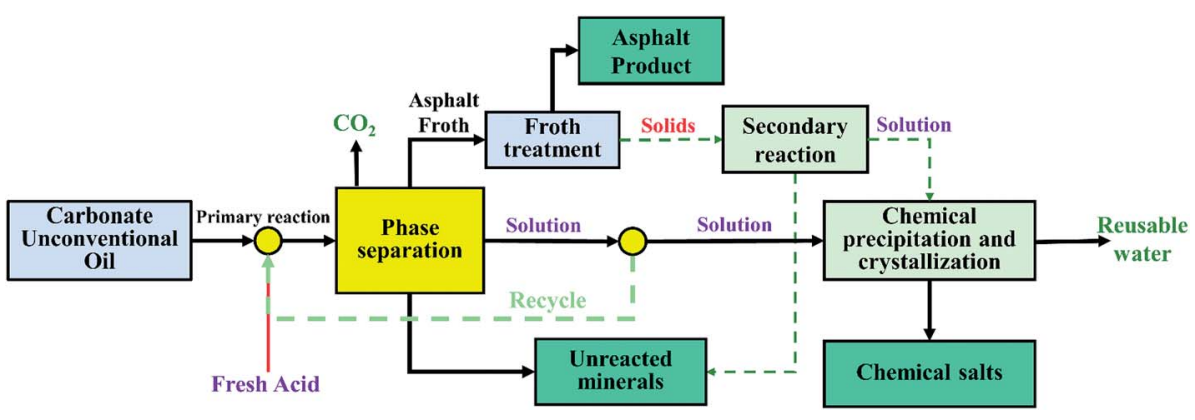

Fig. 1 Schematic diagram of reactive extraction process. 
mineral solids will also be discussed from the aspects of resource utilization and environmental protection. The main purposes are to: (i) find out the effects of operation conditions on extraction efficiency; (ii) understand the roles of formic acid in reactive extraction for asphalt's viscosity reducer and minerals reactants; (iii) explore the mineral redistribution regulations during the reactive extraction for further recovery minerals and acids; (iv) reveal the primary mechanism of the reactive extraction process.

\section{Materials and methods}

\subsection{Materials}

The carbonate asphalt rocks used in this work were obtained from Buton island in Indonesia and their particle size was less than $30 \mu \mathrm{m}$ with a 500-mesh sieve. The composition of the asphalt rocks was determined to possess asphalt (30.41 wt\%), solids (69.33 wt\%) and water (0.26 wt\%) using Dean Stark standard method. ${ }^{\mathbf{1 0}, 38}$ What's more, the raw asphalt rocks was analyzed by XRD (D8-Focus, Bruker, Germany). The main peak position of the XRD spectrum is at $29.40^{\circ}, 39.40^{\circ}$ and $43.15^{\circ}$ in Fig. 2, which means calcite is the main component in carbonate asphalt rocks. Other carbonates, silica and metal oxide was also found by XRD analysis in Fig. 2, while minerals with lower contents and asphalt couldn't be detected by XRD analysis. Table 1 shows the mineral composition of the residual solids after the Dean Stark extraction, which was analyzed by X-ray fluorescence (XRF, Bruker S4 Pioneer, Germany), and min is referred to the elements less than $0.1 \%$ of the minerals by weight. Toluene (analytical grade) and formic acid (88 wt\%) were purchased from Jiangtian Technology Co., Ltd., Tianjin, China. Deionized water was used in all the experiment processes to avoid the influence of external metal ions in industrial water.

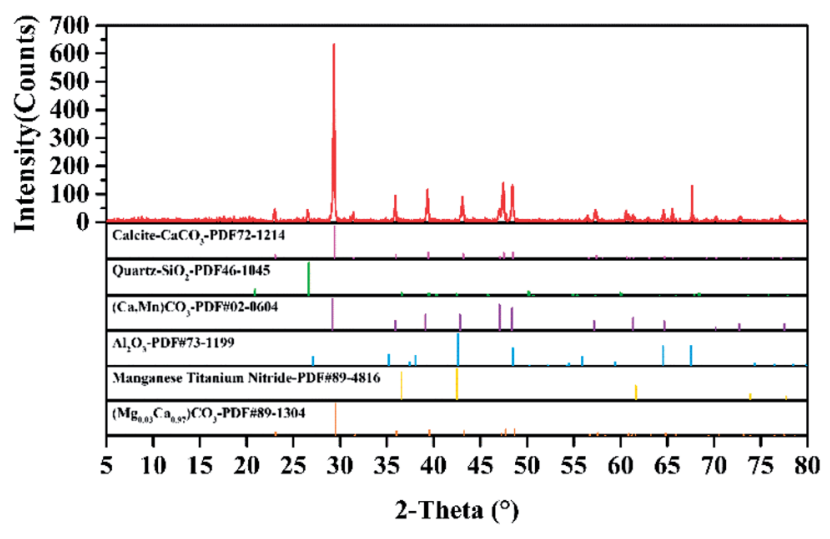

Fig. 2 X-ray diffraction traces of the carbonate asphalt rocks.

\subsection{Reactive extraction process}

3.2.1 Reactive extraction experiment. The asphalt rock particles $(20 \mathrm{~g})$ were mixed with the formic acid solution at different acid concentrations, solid/liquid ratios and temperatures in the reactor. Some of the reactions happened in the reactor, including eqn (1)-(4). ${ }^{35-39}$ Different experimental groups with variable factors are shown in Table 2 . The formic acid was added via a constant pressure funnel to a homemade equipment. A condensing tube was used for cooling the volatile formic acid. The generated gas was exhausted through an air pipe. During the reaction, the asphalt was floated up to the top of the solution and forms the froth. The residual solution was used for further treatment to recover most of metal elements by sequential chemical sedimentation. The by-product of $\mathrm{Ca}(\mathrm{HCOO})_{2}$ could be obtained by crystallizing. The mineral solids which were not reactive with the acids were settled at the bottom of the reactor.

$$
\begin{aligned}
& 2 \mathrm{HCOOH}(\mathrm{aq})+\mathrm{CaCO}_{3}(\mathrm{~s}) \rightarrow \mathrm{CO}_{2}+\mathrm{Ca}(\mathrm{HCOO})_{2}(\mathrm{~s} / \mathrm{aq})+\mathrm{H}_{2} \mathrm{O}(1) \\
& 2 \mathrm{HCOOH}(\mathrm{aq})+\mathrm{MgCO}_{3}(\mathrm{~s}) \rightarrow \\
& \mathrm{CO}_{2}+\mathrm{Mg}(\mathrm{HCOO})_{2}(\mathrm{~s} / \mathrm{aq})+\mathrm{H}_{2} \mathrm{O} \\
& 3 \mathrm{HCOOH}(\mathrm{aq})+\mathrm{Fe}_{2} \mathrm{O}_{3} \rightarrow \mathrm{CO}_{2}+2 \mathrm{Fe}(\mathrm{HCOO})_{2}+3 \mathrm{H}_{2} \mathrm{O} \\
& 6 \mathrm{HCOOH}(\mathrm{aq})+\mathrm{Al}_{2} \mathrm{O}_{3}(\mathrm{~s}) \rightarrow 2 \mathrm{Al}(\mathrm{HCOO})_{3}(\mathrm{aq})+3 \mathrm{H}_{2} \mathrm{O}
\end{aligned}
$$

3.2.2 Asphalt froth products tests. The composition of the froth products obtained at different conditions was measured by Dean-Stark standard method. The viscosity of asphalt product through reactive extraction was measured by rheometer (Brookfield DV-III, America). The element content and information of the oil product was analyzed by CNS elemental analyzer (Vario Micro cube, Germany) and X-ray photoelectron spectroscopy spectra (XPS, X-tool, ULVAC-PHI). The chemical groups of the extracted oil product were detected by Fourier transform infrared spectra (IRAffinity-1S, Japan).

3.2.3 Mineral and solution analysis. The residual solids at the bottom of the reactor and the residual solids entrained in the froth were grounded into fine powder $(10 \mu \mathrm{m})$ separately. These solids were dissolved in HF solution for detecting element content by ICP-OES (Spectro Arcos, Germany). The concentration of ions in solution was also detected by ICP-OES. The element distribution after the reaction was used for evaluating the reaction efficiency. Besides, the residual solids in the froth was analyzed by Fourier Transform Infrared Spectra (IRAffinity-1S, Japan) and X-ray diffractometer (D8-Focus, Bruker, Germany) to further understand the mineral species.

3.2.4 Detection of dissolved organics in the acid solution. During the reaction, it was found that some organics dissolved in the acid solution together with metal ions, as shown in

Table 1 Composition of solids in Indonesian asphalt rocks by XRF (wt\%)

\begin{tabular}{lcccccccccc}
\hline Elements & $\mathrm{CaCO}_{3}$ & $\mathrm{Al}_{2} \mathrm{O}_{3}$ & $\mathrm{Fe}_{2} \mathrm{O}_{3}$ & $\mathrm{~K}_{2} \mathrm{O}$ & $\mathrm{MgO}$ & $\mathrm{P}_{2} \mathrm{O}_{5}$ & $\mathrm{SiO}_{2}$ & $\mathrm{SO}_{3}$ & $\mathrm{TiO}_{2}$ & $\mathrm{Min}$ \\
\hline Indonesian asphalt rocks & 79.47 & 3.61 & 1.69 & 0.53 & 0.70 & 0.58 & 10.57 & 2.34 & 0.17 & 0.34
\end{tabular}


Table 2 The list of experimental conditions for reactive extraction

\begin{tabular}{|c|c|c|c|c|c|c|c|}
\hline Variable factors & $\begin{array}{l}\text { Group } \\
1\end{array}$ & $\begin{array}{l}\text { Group } \\
2\end{array}$ & $\begin{array}{l}\text { Group } \\
3\end{array}$ & $\begin{array}{l}\text { Group } \\
4\end{array}$ & $\begin{array}{l}\text { Group } \\
5\end{array}$ & $\begin{array}{l}\text { Group } \\
6\end{array}$ & Other factors \\
\hline Temperature $\left({ }^{\circ} \mathrm{C}\right)$ & 28 & 38 & 48 & 58 & 67 & 78 & $700 \mathrm{rpm}, 300 \mathrm{ml} / 20 \mathrm{~g}, 100 \mathrm{v} \%$ formic acid \\
\hline Stirring rate $(\mathrm{rpm})$ & 200 & 300 & 500 & 700 & 900 & - & $48^{\circ} \mathrm{C}, 200 \mathrm{ml} / 20 \mathrm{~g}, 100 \mathrm{v} \%$ formic acid \\
\hline Acid dosage (ml) & 50 & 100 & 150 & 200 & 300 & 400 & $38^{\circ} \mathrm{C}, 500 \mathrm{rpm}, 100 \mathrm{v} \%$ formic acid \\
\hline Acid concentration (v\%) & 20 & 40 & 60 & 80 & 100 & - & $38^{\circ} \mathrm{C}, 500 \mathrm{rpm}, 200 \mathrm{ml} / 20 \mathrm{~g}$ \\
\hline
\end{tabular}

Fig. 3a. The formic acid solution was removed by rotary evaporator under the condition of $40{ }^{\circ} \mathrm{C}$ and $15 \mathrm{kPa}$. Then, toluene was added to dissolve the organics followed by a centrifugation at $8000 \mathrm{rpm}$ for 15 minutes to remove some insoluble solids. The metal ions left in the aqueous solution were collected. After three times of centrifugation, the oil phase with toluene and dissolved asphalt components was transferred to a round bottom flask. Then most of toluene was evaporated with rotary evaporating. Finally, the concentrated organic solution was poured into a sloping Petri dish, and dried at $80^{\circ} \mathrm{C}, 15 \mathrm{kPa}$ until the weight of the dish was constant. The obtained organics were brown and viscous as shown in Fig. 3b. They were analyzed by Fourier Transform Infrared Spectra (IRAffinity-1S, Japan) to verify their compositions.

\section{Results and discussion}

\subsection{Asphalt recovery and optimization of operational parameters}

The main purpose of unconventional oil ores separation is to recover heavy oil by removing mineral solids. During the reactive extraction, almost all of asphalt was floated to the top of the solution with little rocks. The froth quality (asphalt/solids) and asphalt recovery (percentage of asphalt in froth to all asphalt) were used to evaluate the results of the reactive extraction. The efficiency of the solid removal is highly dependent on the operational parameters, including reaction temperature, stirring rate, the concentration of acid and the amount of acid, etc.

As shown in Fig. 4a, the asphalt/solid ratio $(\mathrm{A} / \mathrm{S})$ of the asphalt froth increased from 1.48 to 1.83 when the temperature

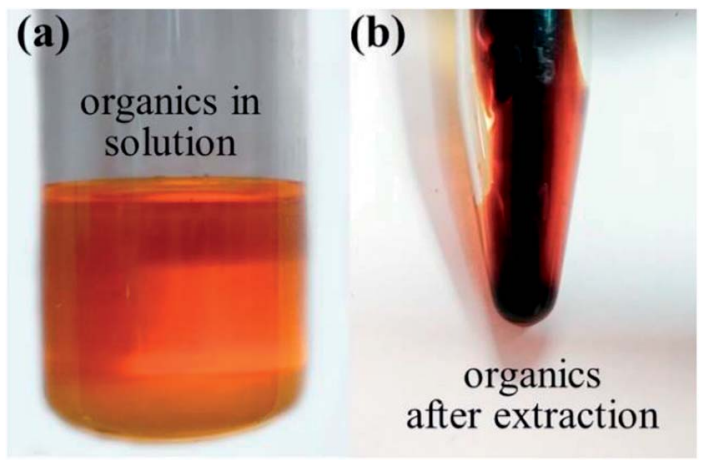

Fig. 3 The organics dissolved in the formic acid solution: (a) the formic acid solution after reactive extraction; (b) the extracted and dried organics. increased from $28{ }^{\circ} \mathrm{C}$ to $68{ }^{\circ} \mathrm{C}$. However, the A/S kept steady when the temperature further increased from $68{ }^{\circ} \mathrm{C}$ to $78{ }^{\circ} \mathrm{C}$. The improvement of $\mathrm{A} / \mathrm{S}$ below $68{ }^{\circ} \mathrm{C}$ is mainly attributed to asphalt viscosity reduction (from solid or semisolid state to fluid or liquid) with increasing temperature. This reduction in asphalt viscosity lead to more chance for acids to contact with mineral solids. Because the lower asphalt viscosity is, the more the mineral surface area exposes. When temperature was higher than $68^{\circ} \mathrm{C}$, the solids in the asphalt froth were kept constant or even increased. This would be mainly ascribed to two reasons: (i) the asphalt appears as fluid which covers the surface of mineral solids more easily and prevents the solid from further reacting with the acids; (ii) the reaction produces a large amount of formates (i.e., $\mathrm{Ca}(\mathrm{HCOO})_{2}$ ) which are exceeded their solubility (18 $\mathrm{g}$ of $\mathrm{Ca}(\mathrm{HCOO})_{2}$ in $100 \mathrm{~g}$ formic acid solution). ${ }^{33,40}$

In Fig. $4 \mathrm{~b}$, the maximum $\mathrm{A} / \mathrm{S}$ (1.6) was obtained at the stirring rate of $700 \mathrm{rpm}$. Further increasing stirring rate contributed slightly to the improvement of A/S. Actually, a proper stirring rate could facilitate the dispersion of rock particles and provide more opportunities for acid-solid contacting and reaction. However, when the agitation is too strong, the acid-solid contacting would be limited because of the gathered sticky asphalt causing by high centrifugal force. This result suggests that the enhancement of $\mathrm{A} / \mathrm{S}$ by solely increasing stirring rate is limited. Strategy on how to disperse oil ores during the reaction is a way to enhance this process.

The influence of concentration of formic acids on $\mathrm{A} / \mathrm{S}$ has been shown in Fig. 4c. The $\mathrm{A} / \mathrm{S}$ ratio of the froth increased from 1.23 to 1.80 when the concentration of formic acid increased from $20 \%$ to $100 \%$. High concentration of formic acid could provide more $\mathrm{H}^{+}$for reaction to convert minerals to ions. Meanwhile, the high concentration could also act as diluent to dissolve asphalt, allowing the reduction of the asphalt recovery (Fig. 4). Consequently, more mineral surface could be exposed to contact with the acids and then the reaction was enhanced. Similarly, the optimized dosage of formic acids was $200 \mathrm{ml} / 20 \mathrm{~g}$ ores which could obtain a froth quality with $\mathrm{A} / \mathrm{S}$ at 1.81 . However, as can be observed, the A/S decrease lightly with keeping increasing the dosage of formic acid from $200 \mathrm{ml}$ to $400 \mathrm{ml}$. One of the possible reasons is more asphalt dissolute in more formic acid, which reducing the asphalt content in asphalt products. In summary, the final optimal conditions of reactive extraction are $68{ }^{\circ} \mathrm{C}, 200 \mathrm{ml} \mathrm{100 \%}$ formic acid and $700 \mathrm{rpm}$.

The percentage of floated asphalt in different conditions is shown in Fig. 5. The floated asphalt is determined to be asphalt obtained from the froth on the top of the solution after reactive 

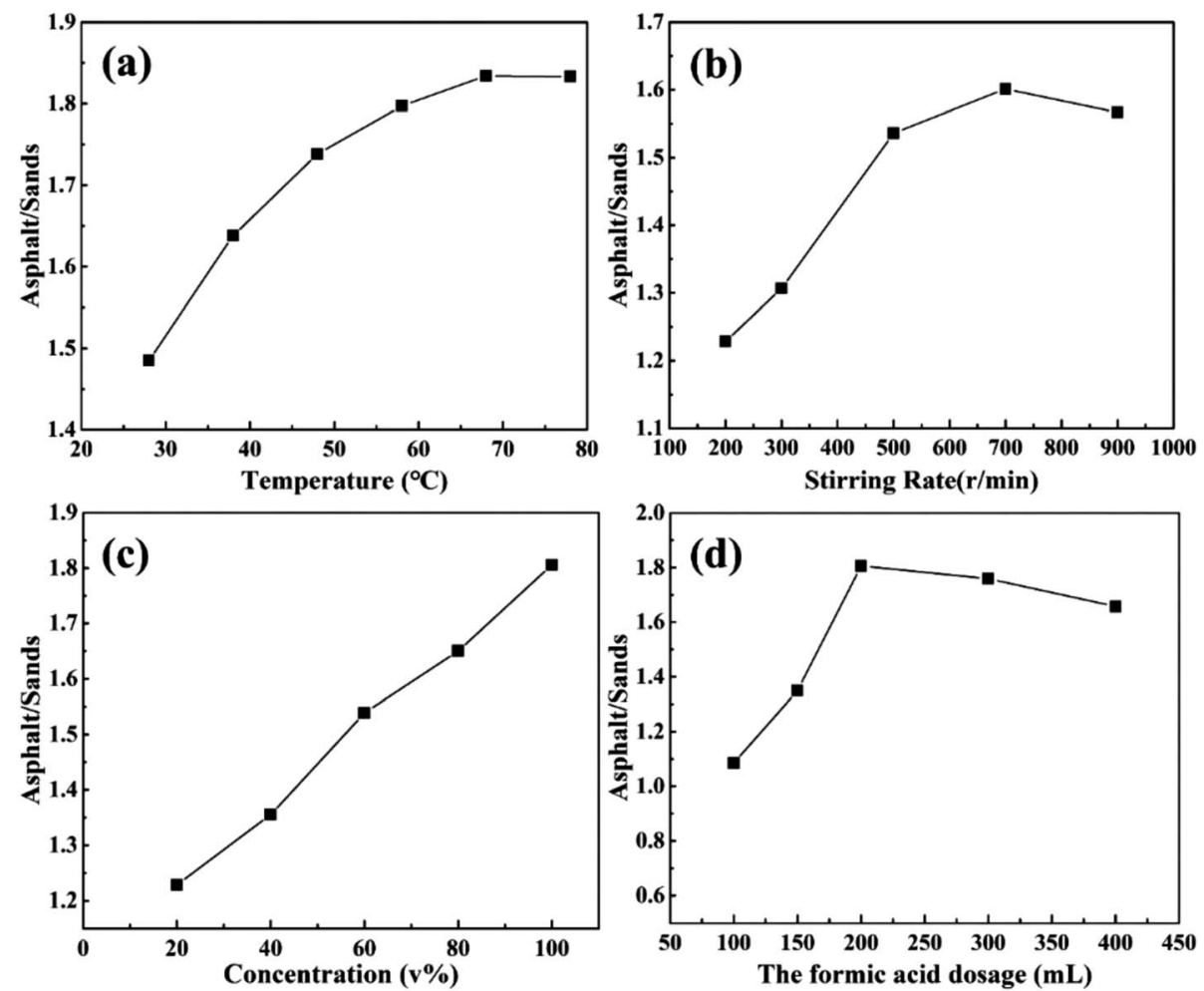

Fig. 4 Asphalt froth quality as a function of: (a) temperature, (b) stirring rate, (c) concentration of formic acid, and (d) formic acid dosage.

extraction. More than $70 \%$ of asphalt could be floated to the top of the solution at different conditions with average floated asphalt of $84.53 \%$. The maximum floated asphalt is $94.9 \%$, that means asphalt is basically recovered. This floated asphalt could reach $100 \%$ in industrial production due to its full flotation.

\subsection{Mineral redistribution after the reactive extraction}

The minerals in the asphalt rocks redistributed in different phases after the reactive extraction. Most of carbonate

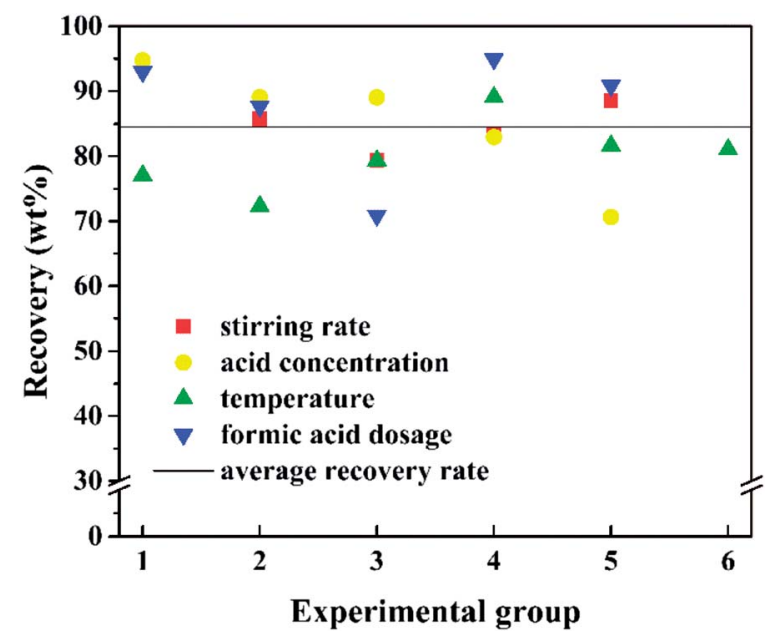

Fig. 5 The percentage of asphalt froth on the top of the solution under different lab conditions. minerals and metal oxides were dissolved into acid solution because of their reaction with acids. Some minerals were entrained in the asphalt and stayed in the froth. In addition, only a little of non-reactive minerals (i.e., quartz and clays) were settled down to the bottom of the reactor. To further investigate dissolution of formic acid to gravel and migration of metallic elements. The residual solids in different phases after reactive extraction were characterized, and the results were shown in Fig. 6-8. Fig. 6 shows the mass fraction of different elements in different phases and these elements were divided into highly dissolved and poorly dissolved elements by a dotted line. As shown in the highly dissolved area, 93.14\% of $\mathrm{Ca}$ is dissolved, while $4.07 \%$ of $\mathrm{Ca}$ is entrained into the upper asphalt froth and the other $2.79 \%$ is settled to the bottom. Among the mineral components, $\mathrm{Mg}$ (61.12\%), $\mathrm{Cr}(50.62 \%), \mathrm{Ni}$ $(50.10 \%), \mathrm{S}(47.09 \%)$, and $\mathrm{P}(84.67 \%)$ are dissolved in the formic acid solution during the reactive extraction process. Some of the insoluble element including $\mathrm{Mg}$ (37.47\%), $\mathrm{Cr}$ (43.82\%), Ni (45.03\%), S (33.44\%) and P (13.93\%) are mainly concentrated in the upper asphalt froth, and $19.50 \%$ of $S$ were settled down to the bottom of the reactor. In addition, the distributed of poorly dissolved elements including $\mathrm{Al}, \mathrm{Cu}, \mathrm{Fe}$, $\mathrm{Zn}, \mathrm{Zr}$, Ti and Si are also shown in Fig. 6. The elements of $\mathrm{Ti}$ and $\mathrm{Si}$ are almost insoluble in formic acid. Only a small part of minerals with $\mathrm{Al}(9.84 \%), \mathrm{Cu}(23.40 \%), \mathrm{Fe}$ (39.50\%), $\mathrm{Zn}$ (15.100\%) and $\mathrm{Zr}(15.83 \%)$ are dissolved in formic acid, while most of these insoluble elements were gathered in the upper asphalt froth. To further explore the existence ores of these elements, FITR and XRD analysis were conducted. 


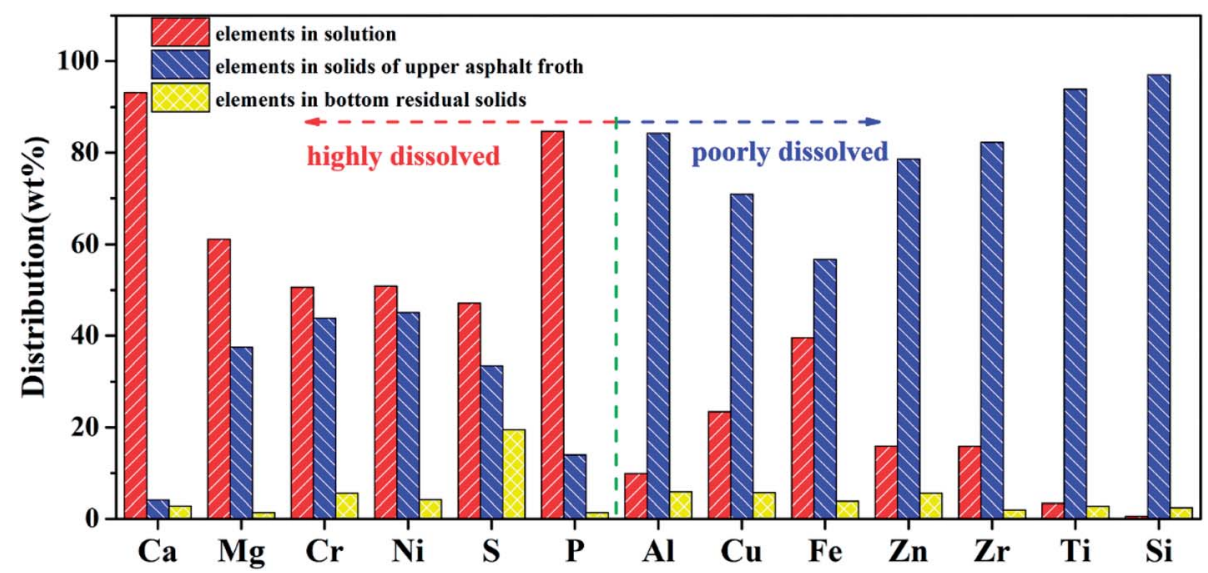

Fig. 6 Redistribution of elements in different phases.

The characteristic peaks for calcium carbonate are mainly located at $1423 \mathrm{~cm}^{-1}$ (the antisymmetric stretching absorption of $\mathrm{C}-\mathrm{O}$ bonds), $1804 \mathrm{~cm}^{-1}$ (the stretching absorption of $\mathrm{C}-\mathrm{O}$ bonds), $876 \mathrm{~cm}^{-1}$ (the out-of-plane deformation vibration absorption of $\mathrm{CO}_{3}{ }^{2-}$ ), and $706 \mathrm{~cm}^{-1}$ (the in-of-plane deformation vibration absorption of $\mathrm{O}-\mathrm{C}-\mathrm{O}$ bonds). These peaks are clearly shown in residual sands in products in Fig. 7. What's more, the peaks of soxhlet extraction residual sands at $29.40^{\circ}$, $39.40^{\circ}, 43.15^{\circ}, 47.49^{\circ}, 48.51^{\circ}$ in Fig. 8 confirmed this result. There are some small miscellaneous peaks at $26.51^{\circ}, 33.04^{\circ}$ and so on, showing the presence of silica and other minerals. While for the solids after reactive extraction, these characteristic peaks disappeared, while the peaks at $1036 \mathrm{~cm}^{-1}$ (the antisymmetric stretching absorption of Si-O-Si bonds) and $471 \mathrm{~cm}^{-1}$ (the symmetric stretching absorption of Si-O bonds) are detected, indicating that the silica solids are the main minerals in the entrained solids. The results are further confirmed by the XRD detection where the peaks located at $26.64^{\circ}$ and $26.70^{\circ}$ (Fig. 8). The characteristic peaks for phosphate are obvious when the amount of $\mathrm{CaCO}_{3}$ reduced after reactive extraction, locating at $1363 \mathrm{~cm}^{-1}$ (the stretching vibration absorption peak of $\mathrm{P}-\mathrm{O}$ bonds), $1613 \mathrm{~cm}^{-1}$ (the combined spectrum of stretching vibration and bending vibration of $\mathrm{P}-\mathrm{O}$ ) and $530 \mathrm{~cm}^{-1}$ (the in-

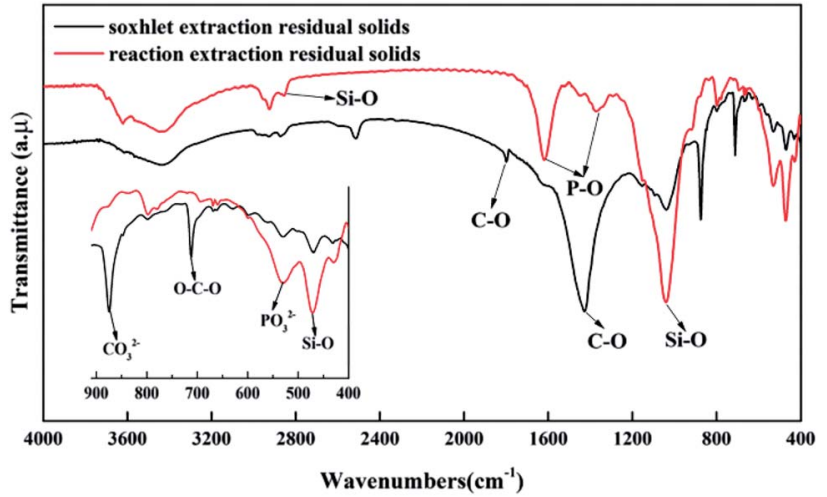

Fig. 7 FTIR of residue sands after reactive extraction or Soxhlet extraction.

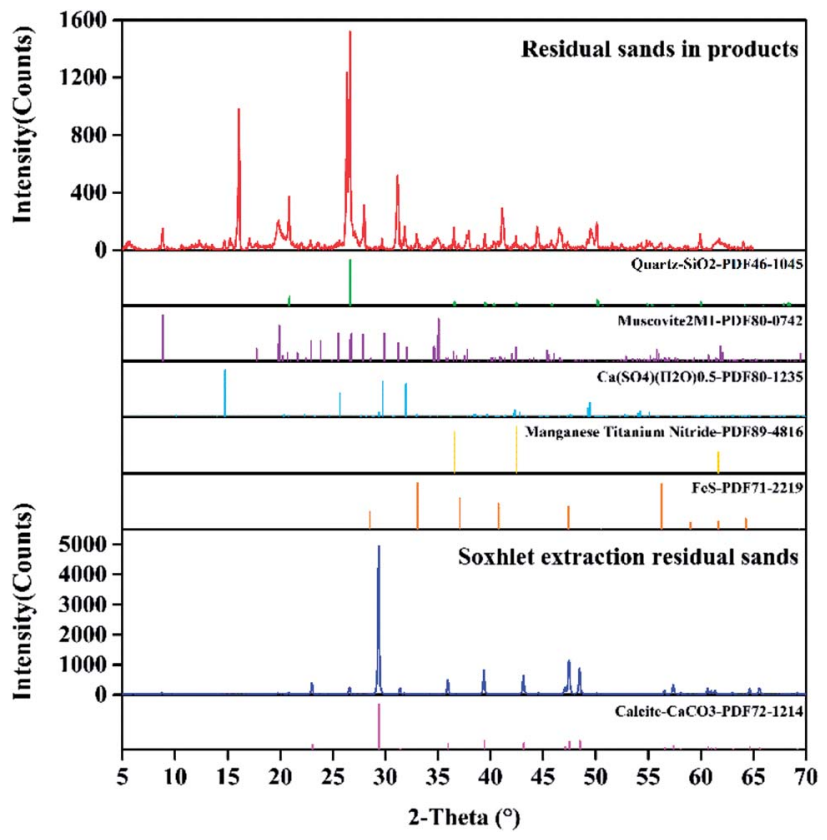

Fig. 8 X-ray diffraction traces of residual sands after reaction extraction and soxhlet extraction.

plane bending vibration of the phosphate group). In Fig. 8, the peaks of residual solids in products at $33.04^{\circ}, 26.51^{\circ}, 42.47^{\circ}$, $8.85^{\circ}$, and $35.06^{\circ}$ on the XRD graph were corresponding to the main peaks of iron sulfide, manganese titanium nitride, hydrous calcium sulphate and muscovite respectively. These chemicals cannot react with formic acid. In addition, due to lipophilicity of these minerals, they are more easily migrating into the asphalt froth. ${ }^{41,42}$ Therefore, to further improve the froth quality, more efforts should be made to separate these particles.

\subsection{Roles of formic acids on asphalt viscosity reduction}

According to the experimental phenomena, the asphalt was more fluidic after the reactive extraction. To understand what 


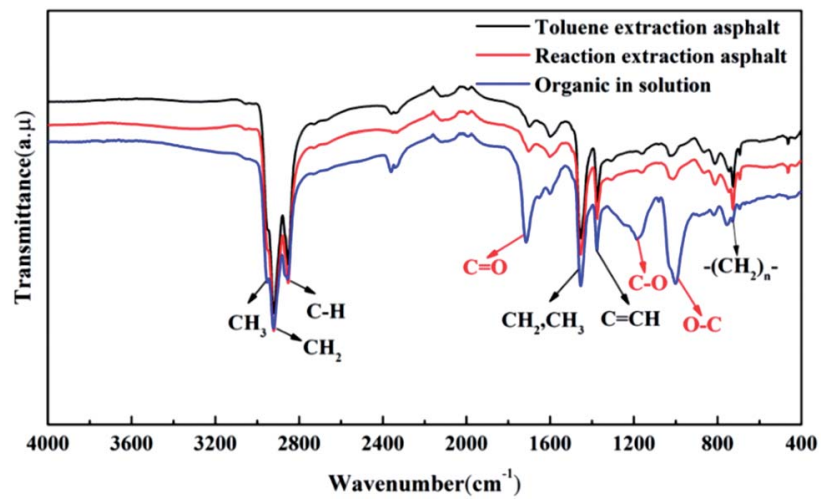

Fig. 9 FTIR spectra of asphalt from reactive extraction (black), toluene extraction (red) and organic in solution (blue).

happened to the asphalt during the reaction, the viscosity of the asphalt has been tested at $60^{\circ} \mathrm{C}$. Results show that the viscosity of formic acid extracted asphalt is about $24.39 \mathrm{~Pa} \mathrm{~s}$, which is much lower than that of toluene extracted asphalt (123.67 Pa s). This reduction in asphalt viscosity suggests that some external chemicals may be mixed with the asphalt. ${ }^{43}$

Fig. 9 presents the FTIR spectra of the asphalts obtained by toluene extraction and formic acid reactive extraction. Obviously, the difference in chemical groups between two asphalts are small: both of the asphalts possess the similar chemical groups, including the asymmetrical stretch vibration absorption of $\mathrm{C}-\mathrm{H}_{3}$ bonds $\left(2951 \mathrm{~cm}^{-1}\right)$, the symmetric and asymmetrical stretch vibration absorption of $\mathrm{C}-\mathrm{H}_{3}$ bonds $\left(2851 \mathrm{~cm}^{-1}\right.$ and $2918 \mathrm{~cm}^{-1}$ ), the overlap of symmetric stretch vibration absorption of $\mathrm{CH}_{2}$ and $\mathrm{CH}_{3}\left(1453 \mathrm{~cm}^{-1}\right)$, the inner-of -plane deformation vibration of $-\mathrm{C}=\mathrm{C}-\left(1373 \mathrm{~cm}^{-1}\right)$ and the out-of-

Table 3 The elemental analysis of asphalt (wt\%)

\begin{tabular}{llllllll}
\hline Sample & C & H & O & N & S \\
\hline
\end{tabular}

$\begin{array}{llllll}\text { Bitumen from toluene extracted } & 81.505 & 9.595 & 1.170 & 0.475 & 6.640\end{array}$ $\begin{array}{llllll}\text { Bitumen from reactive extracted } & 80.965 & 9.680 & 1.920 & 0.415 & 6.535\end{array}$ plane deformation vibration of $-\left(\mathrm{CH}_{2}\right)_{n}-\left(730 \mathrm{~cm}^{-1}\right)$. Further tests were conducted to confirm the role of formic acids in reduce asphalt viscosity. Table 3 presents element analysis of these two asphalts. The results show that the contents of hydrogen, sulfur, and nitrogen in formic acid extracted asphalt are similar to those in the toluene extracted asphalt. However, compared with the toluene extracted asphalt, carbon content is decreased while oxygen content is increased in the asphalt from formic acid reactive extraction. These changes suggest that the asphalt would be mixed with some formic acids during the reactive extraction. The oxygen-based groups would provide polar groups, which is able to establish hydrogen bond with asphaltenes by replacing some original interactions in asphalt macromolecules and destroying the overlapping structure of asphalt molecules. Consequently, the viscosity of the asphalt was reduced. ${ }^{43-45}$

The above results are further confirmed by high resolution XPS spectra of C1s and O1s of asphalts (Fig. 10 and 11). The C-H bonds are corresponded to the C1s peak of $285.2 \mathrm{eV}$, which increased after reaction. It means that the formyloxy group was mixed in the asphalt. However, for the $\mathrm{C}=\mathrm{C}$ groups $(284.6 \mathrm{eV})$, they changed slightly before and after the reactive extraction. Moreover, the O1s peaks are divided into three peaks at $531.2 \mathrm{eV}, 532.3 \mathrm{eV}, 533.5 \mathrm{eV}$, which corresponded to $\mathrm{C}=\mathrm{O}, \mathrm{C}-\mathrm{O}$, $\mathrm{O}-\mathrm{C}=\mathrm{O}$ groups, respectively. The contents of $\mathrm{C}=\mathrm{O}$ and $\mathrm{O}-\mathrm{C}=\mathrm{O}$ groups increased after reaction. This increase in oxygenated group is mainly contributed to the mixing of formyloxy group, which further confirmed the dissolution of formic acid in asphalt.

\subsection{Recovery of materials from acid solution}

Most of the minerals could be dissolved in formic acid during extractive reaction process, especially calcium carbonate. The ion concentrations in the solution after extraction were detected by ICP-OES, shown in Fig. 12. The mass concentrations of Ca, $\mathrm{Fe}, \mathrm{Ni}, \mathrm{Mg}, \mathrm{Al}$ are $13.53 \mathrm{mg} \mathrm{ml}^{-1}, 0.17 \mathrm{mg} \mathrm{ml}^{-1}, 0.07 \mathrm{mg} \mathrm{ml}^{-1}$, $0.14 \mathrm{mg} \mathrm{ml}^{-1}, 0.03 \mathrm{mg} \mathrm{ml}^{-1}$ respectively. Due to the reducibility of formic acid, Fe exists in the state of $\mathrm{Fe}^{2+}$ in the solution. ${ }^{34}$ The
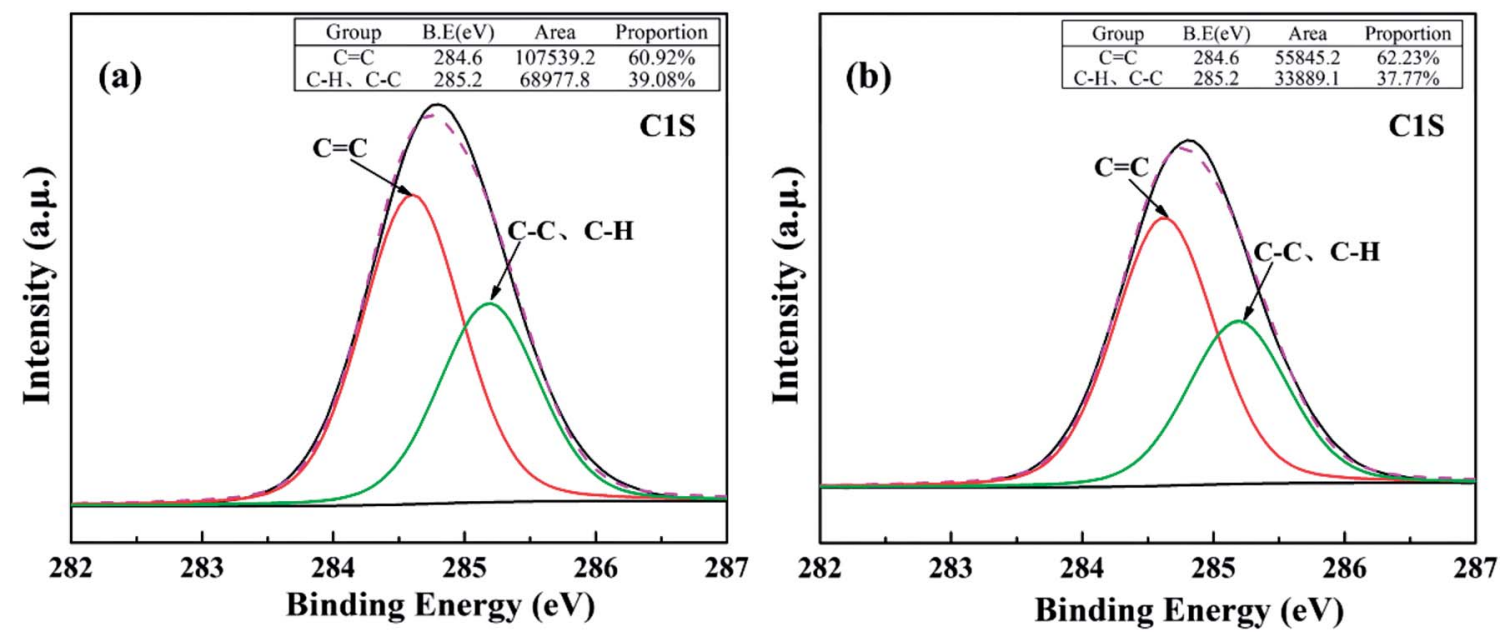

Fig. 10 Curve fitting of $\mathrm{C} 1 \mathrm{~s}$ photoelectron peaks of asphalt from (a) reactive extraction, (b) toluene extraction. 

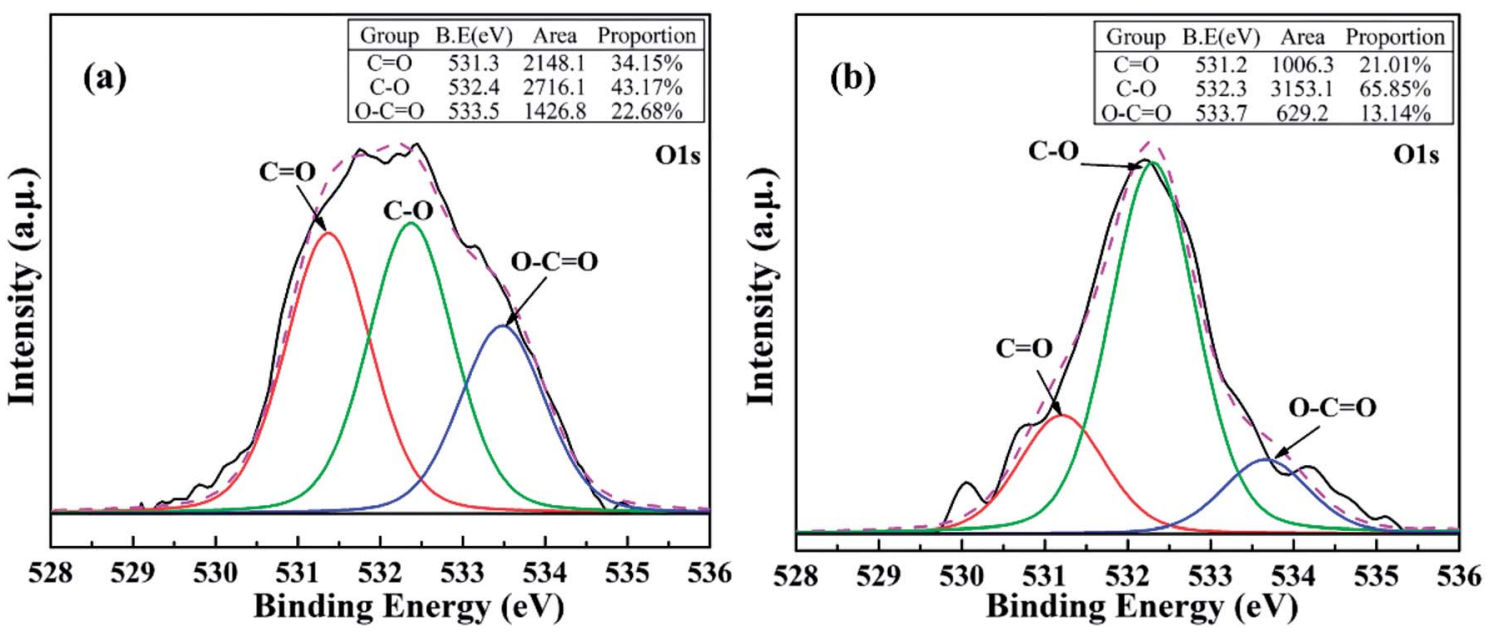

Fig. 11 Curve fitting of O1s photoelectron peaks of asphalt from (a) reactive extraction, (b) toluene extraction.

concentration of other ions was less than $0.001 \mathrm{mg} \mathrm{ml}^{-1}$. In addition, reacting with these minerals consumes $0.5 \%$ of $200 \mathrm{ml}$ formic acid, which means formic acid could be recycled and reused.

In addition to the above metal ions, it is found that there are about $0.1 \mathrm{~g}$ of organic materials from the asphalt sample $(\sim 6 \mathrm{~g})$ being dissolved in formic acid, as shown in Fig. 9. Results showed that except for the $\mathrm{C}-\mathrm{H}, \mathrm{C}=\mathrm{C}$ groups, there are other characteristic peaks appearing in these organics. These peaks were mainly located at $1715 \mathrm{~cm}^{-1}$ (the stretch vibration absorption of $\mathrm{C}=\mathrm{O}$ bonds), $1171 \mathrm{~cm}^{-1}$ (the stretch vibration absorption of $\mathrm{C}-\mathrm{O}$ bonds), and $1001 \mathrm{~cm}^{-1}$ (the stretch vibration absorption of $\mathrm{O}-\mathrm{C}$ bonds). These findings suggested that the organic materials dissolved in the solution were mainly ester hydrocarbons.

Accordingly, a simple process for element recovery was proposed including the process of organic matter recycle, chemical precipitation and crystallization as shown in Fig. 13. Toluene was used to extract the organic materials from the aqueous solution. After the extraction, the solution was separated into two phases as shown in Fig. 13a. The organic materials could be recovered from the upper phase when removing

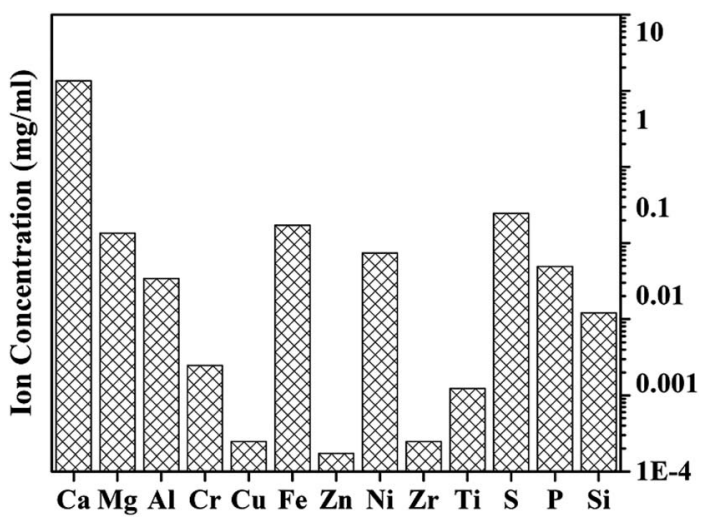

Fig. 12 Ion concentration in formic acid solution by ICP-OES. the solvent. The inorganic materials were recovered by chemical precipitation through the addition of alkaline substances. The lab tests showed that the Fe could be chemically precipitated at pH 7.4 (Fig. 13b), while Mg would be mostly precipitated at 9.7 (Fig. 13c). According the calculation, $\mathrm{Cu}, \mathrm{Al}, \mathrm{Zr}$, Ti and $\mathrm{Ni}$ would be settled together with $\mathrm{Fe}$, while $\mathrm{Zn}$ and $\mathrm{Cr}$ are mostly precipitated together with $\mathrm{Mg}$. After the chemical precipitation and filtration, the filtrate was crystallized by evaporating the water. The obtained crystal product of $\mathrm{Ca}(\mathrm{HCOO})_{2}$ could reach the industrial grade (purity of 98.8\%), shown in Fig. 13d. This primary test suggests that minerals and the externally added acids could be recovered with valuable by-products $\left(\mathrm{Ca}(\mathrm{HCOO})_{2}\right)$. Other detailed work is still ongoing.

\subsection{Mechanism of the reactive extraction}

According to above results and discussions, the reactive extraction process could be understood from the following substages, shown in Fig. 14. At the beginning, the formic acids react with the exposed mineral surface when the acid solution was added. Most of the carbonate minerals were dissolved into the solution. During the reaction, $\mathrm{CO}_{2}$ would be generated. Some of the $\mathrm{CO}_{2}$ will be released to the solution as bubbles and rise to the top of the solution. While, some of the $\mathrm{CO}_{2}$ will attach with the asphalt, leading to the density reduction of asphalt. These $\mathrm{CO}_{2}$ bubbles will help the flotation of asphalt to the top of the solution. Because of the deformation, coalescence and rupture of $\mathrm{CO}_{2}$ bubbles during the stirring and flotation, the asphalt will form froth with water, unreacted solids, $\mathrm{CO}_{2}$ bubbles. In addition to dissolving minerals, formic acid could diffuse into the asphalt, leading to the reduction of the asphalt viscosity. This reduction in asphalt viscosity further increases the exposure of mineral solids to the solution, facilitating the reaction between minerals and acids. The relatively inert solids, such as $\mathrm{SiO}_{2}$, will not react with acids. Therefore, little of them would be settled to the bottom of the reactor during the reaction, while others would be migrated to the asphalt froth. Additionally, some of 


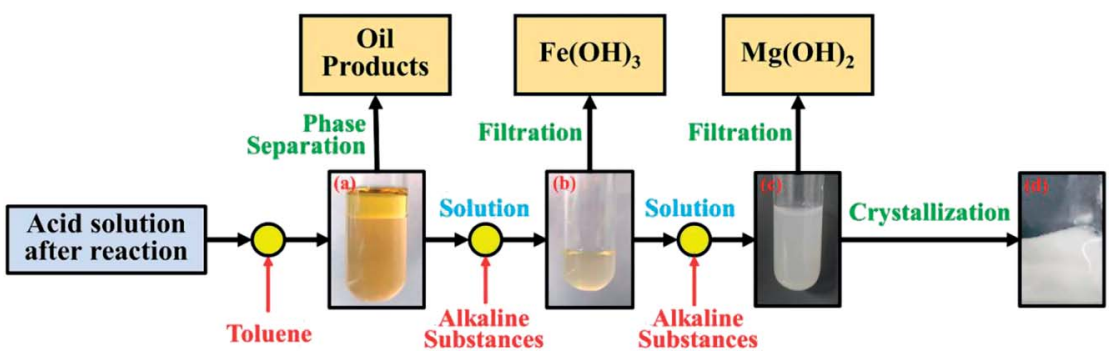

Fig. 13 Experimental images of organics and elements recovering. (a) Organics and formic acid were separated into two phases after toluene extraction; (b) iron ions began to precipitate; (c) magnesium ions began to precipitate; (d) $\mathrm{Ca}(\mathrm{HCOO})_{2}$ product after crystallized.

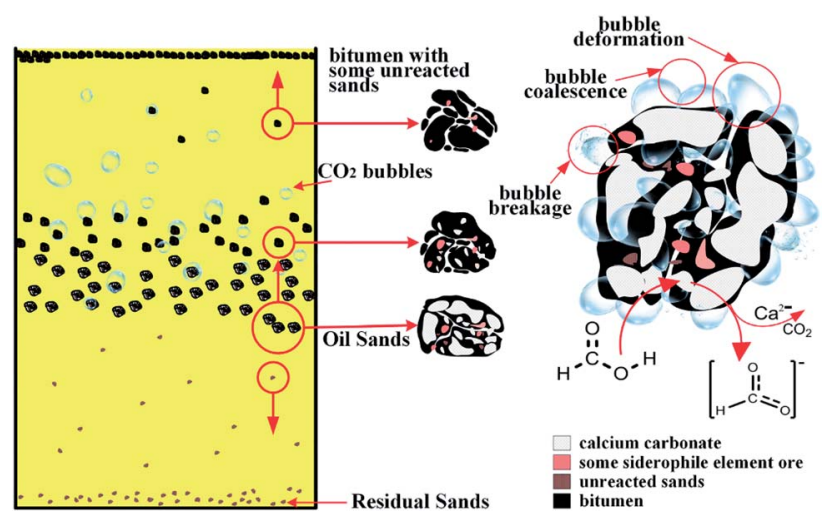

Fig. 14 Schematic diagram of the whole reaction process and detail magnification in the process.

soluble oxygenated hydrocarbons would be dissolved into the solution.

\section{Conclusions}

A reactive extraction process was proposed to recover asphalt and minerals from the carbonate unconventional oil resources by formic acid. The optimal operating conditions is $68{ }^{\circ} \mathrm{C}$, $700 \mathrm{rpm}, 100 \mathrm{v} \%$ formic acid and $200 \mathrm{ml}$ formic acid and asphalt recovery could reach $94.9 \%$. During the process, the minerals would be redistributed in different phases: $93.14 \%$ of $\mathrm{Ca}$ and most $\mathrm{Mg}, \mathrm{Cr}$, Ni in ores would be dissolved in the solution; insoluble elements like $\mathrm{Zn}, \mathrm{Zr}, \mathrm{Al}, \mathrm{Cu}$ and $\mathrm{Si}$ would be migrated to the asphalt froth; minerals like silica, manganese titanium nitride, hydrous calcium sulphate and muscovite are mainly settled as residual solids. Formic acid solution could be recycled and reused, what's more, metal ions concentration would accumulation for further recovered by chemical precipitation and crystallization. A valuable by-product $\mathrm{Ca}(\mathrm{HCOO})_{2}$ (98.8\% purity) could be obtained for industrial application. Meanwhile, the formic acid is found to be able to diffuse into asphalt and cause viscosity reduction which enhances the reactive extraction. These primary results suggest the potential feasibility of reactive extraction for the separation of carbonate unconventional oil ores. It not only fully recover asphalt, but also recover minerals as high value by-products without waste production and tailing accumulation.

\section{Conflicts of interest}

The authors are devoted to commercialize the reactive extraction process for the exploitation of Indonesian asphalt rocks or similar unconventional oil ores.

\section{Acknowledgements}

This work was financially supported by Municipal Natural Science Foundation of Tianjin (Grant 18JCQNJC06500) and the National Natural Science Foundation of China (No. 21506155, No. 41471258).

\section{References}

1 L. He, F. Lin, X. Li, H. Sui and Z. Xu, Chem. Soc. Rev., 2015, 44, 5446-5494.

2 J. Czarnecki, B. Radoev, L. L. Schramm and R. Slavchev, Adv. Colloid Interface Sci., 2005, 114-115, 53-60.

3 X. Li, L. He, G. Wu, W. Sun, H. Li and H. Sui, Energy Fuels, 2012, 26, 3553-3563.

4 S. Srinivasa, C. Flury, A. Afacan, J. Masliyah and Z. Xu, Energy Fuels, 2012, 26, 2883-2890.

5 J. Hupka, J. D. Miller and J. Drelich, Can. J. Chem. Eng., 2004, 82, 978-985.

6 J. Masliyah, Z. J. Zhou, Z. Xu, J. Czarnecki and H. Hamza, Can. J. Chem. Eng., 2004, 82, 628-654.

7 K. Clark and D. Pasternack, Ind. Eng. Chem., 1932, 24, 14101416.

8 L. He, X. G. Li, Y. L. Du, G. Z. Wu, H. Li and H. Sui, Adv. Mater. Res., 2011, 347-353, 3728-3731.

9 K. Pal, L. d. P. Nogueira Branco, A. Heintz, P. Choi, Q. Liu, P. R. Seidl and M. R. Gray, Energy Fuels, 2015, 29, 2261-2267.

10 H. Sui, G. Ma, L. He, Z. Zhang and X. Li, Energy Fuels, 2016, 30, 9242-9249.

11 E. O. Odebunmi and A. G. Olaremu, Open J. Appl. Sci., 2015, 05, 485-494.

12 Z. Wang, X. Liu, Y. Wang, L. Liu, H. Wang, S. Deng and Y. Sun, J. Therm. Anal. Calorim., 2015, 123, 1707-1714.

13 F. Nie, D. He, J. Guan, H. Bao, K. Zhang, T. Meng and Q. Zhang, Energy Fuels, 2017, 31, 1318-1328.

14 P. Tiwari and M. Deo, AIChE J., 2012, 58, 505-515.

15 C. Jia, Z. Wang, H. Liu, J. Bai, M. Chi and Q. Wang, J. Anal. Appl. Pyrolysis, 2015, 114, 250-255. 
16 S. Li, J. wang, H. Tan and Z. Wu, Fuel, 1995, 74, 1191-1193. 17 A. Eshraghian and M. M. Husein, Fuel, 2017, 190, 396-408.

18 H. Sui, L. Xu, X. Li and L. He, Chem. Eng. J., 2016, 290, 312318.

19 Z. Zhang, H. Li, H. Sui, L. He and X. Li, $R S C A d v .$, 2018, 8, 15813-15824.

20 H. Sui, J. Zhang, Y. Yuan, L. He, Y. Bai and X. Li, Can. J. Chem. Eng., 2016, 94, 1191-1196.

21 P. Painter, P. Williams and A. Lupinsky, Energy Fuels, 2010, 24, 5081-5088.

22 J. R. Vanderveen, J. Geng, S. Zhang and P. G. Jessop, RSC Adv., 2018, 8, 27318-27325.

23 H. Pakdel and C. Roy, Energy Fuels, 2003, 17, 1145-1152.

24 Q. Wang, C. Wang, Q. Jia, Y. Wang and D. Wu, Fuel Process. Technol., 2012, 99, 110-114.

25 S. Li and C. Yue, Fuel Process. Technol., 2004, 85, 51-61.

26 T. Xu, H. Wang, X. Huang and G. Li, Fuel, 2013, 105, 757-763.

27 I. M. Devianto, B. H. Susanto and M. Nasikin, Chem. Mater. Eng., 2013, 1, 35-42.

28 M. Gharabaghi, M. Irannajad and M. Noaparast, Hydrometallurgy, 2010, 103, 96-107.

29 M. Ashraf, Z. I. Zafar and T. M. Ansari, Hydrometallurgy, 2005, 80, 286-292.

30 L. Koech, R. Everson, H. Neomagus and H. Rutto, J. Air Waste Manage. Assoc., 2015, 65, 126-132.

31 L. Chou, R. M. Garrels and R. Wollast, Chem. Geol., 1989, 78, 269-282.

32 C. N. Fredd and H. S. Fogler, Chem. Eng. Sci., 1998, 53, 38633874 .
33 L. Kalfayan, Production Enhancement with Acid Stimulation, PennWell Corporation, Oklahoma, 2 edn, 2008.

34 D. E. Nierode and B. B. Williams, Soc. Pet. Eng. J., 1971, 11, 406-418.

35 N. Raza, Z. I. Zafar and M. Najam-ul-Haq, Hydrometallurgy, 2014, 149, 183-188.

36 M. Buijse, P. de Boer, B. Breukel, M. Klos and G. Burgos, presented in part at the SPE European Formation Damage Conference, The Hague, Netherlands, 2003.

37 X. Li, H. Sui, L. He, C. Xu, S. Cong, H. Yang, L. Xu, Y. Yue and Y. Li, Efficient separation method and system for the recovery of heavy oil from unconventional oil ores with rich carbonates, Chinese patent, CN105861015A, 2016.05.09.

38 E. W. Dean and D. D. Stark, J. Ind. Eng. Chem., 1920, 12, 486490.

39 A. C. Braithwaite, A. C. Eaton and P. S. Groom, Fert. Res., 1989, 19, 175-181.

40 A. Punase, Doctor thesis, Texas A\&M University, 2015.

41 E. Roth, T. Bank, B. Howard and E. Granite, Energy Fuels, 2017, 31, 4714-4720.

42 B. Bicalho, I. Grant-Weaver, C. Sinn, M. W. Donner, S. Woodland, G. Pearson, S. Larter, J. Duke and W. Shotyk, Fuel, 2017, 206, 248-257.

43 R. Li, C. Wang, P. Wang and J. Pei, Fuel, 2016, 181, 935-941. 44 J. Argillier, L. Barre, F. Brucy, J. Dournaux, I. Henaut and R. Bouchard, presented in part at the Society of Petroleum Engineers, Porlamar, Venezuela, 12-14 March, 2001.

45 A. Erceg Kuzmić, M. Radošević, G. Bogdanić, V. Srića and R. Vuković, Fuel, 2008, 87(13), 2943-2950. 